\title{
‘CINECONVERSAS’ - CRIANDO CURRÍCULOS COM FILMES DE MIGRAÇÃO
}

\author{
Marcelo Ferreira Machado* \\ Universidade do Estado do Rio de Janeiro, Brasil \\ mar_chado@hotmail.com \\ Maria Morais** \\ Universidade do Estado do Rio de Janeiro, Brasil \\ mariamoraiss@yahoo.com.br \\ Noale Toja*** \\ Universidade do Estado do Rio de Janeiro, Brasil \\ noaletoja22@gmail.com
}

Recibido: 13/08/2019 Aceptado: 7/02/2020

\section{Resumo}

Ao percebermos a potência dos usos dos filmes e da produção audiovisual como dispositivos fomentadores de conversas, catalisadores de ideias, sensações, sentimentos, fomos tecendo 'conhecimentosignificações' e pudemos agregar outros valores para a pesquisa, como a ludicidade, a criatividade e o compartilhamento.

Trazer o tema 'migração', por meio de filmes, questão urgente nos tempos atuais, nos aproxima desses acontecimentos com sensibilidade, incorporando-os às nossas realidades, já que compreendemos esses processos migratórios como as relações vividas por cada um de nós e pelos nossos familiares, seja vindo de outros países, vindo de outros estados, cidades, bairros, diferentes territórios, guetos, facções, culturas, sentimentos. Essas sensações podem nos aproximar de realidades criadas nas diferentes redes educativas que formamos e que nos formam. Ao tratar de migração ou refúgio com Cineconversas, metodologia desenvolvida no grupo de pesquisa, lidamos com artefatos e componentes curriculares, criamos um caminho de aproximação entre limites e fronteiras a que estamos submetidos o tempo todo como migrantes ou estrangeiros em diferentes situações da vida cotidiana.

Palavras chaves: Migração - Redes Educativas - Cotidianos - Cineconversas - Cinema.

\section{Resumen}

Cuando nos dimos cuenta del poder de los usos de las películas y la producción audiovisual como dispositivos que fomentan conversaciones, catalizadores de ideas, sensaciones,

\footnotetext{
* Geógrafo pela UFRJ. Especialista em Tendências do Ensino de Geografia. Mestre em Processos Formativos e Desigualdade Social - FFP/UERJ. Doutorando em Educação. Coordenador Pedagógico e Professor em escolas públicas e privadas do Rio de Janeiro.

**Pedagoga - UFRJ. Mestra e Doutorando em Educação (UERJ). Bolsista Faperj. Professora mediadora do Consórcio CEDERJ/UERJ.

***Doutorando em Educação - PropEd/UERJ. Linha de pesquisa "Cotidianos, redes educativas e processos culturais" junto ao GRPesq Currículos, redes educativas, imagens e sons. Desenvolve projeto nas áreas das artes e tecnologias. Bolsa Faperj.
} 
sentimientos, comenzamos a tejer 'conocimentossignificaciones'y pudimos agregar otros valores para la investigación, como el lúdico, la creatividad y el compartir.

Traer el tema 'migración' a través de películas, un tema urgente en los tiempos actuales, nos acerca a estos acontecimientos con sensibilidad, incorporándolos a nuestras realidades, ya que entendemos estos procesos migratorios como las relaciones experimentadas por cada uno de nosotros y nuestros miembros de la familia, ya sea de otros países, de otros estados, ciudades, barrios, diferentes territorios, guetos, facciones, culturas, sentimientos. Estas sensaciones pueden acercarnos a las realidades creadas en las diferentes redes educativas que formamos y que nos forman. Cuando se trata de migración o refugio con Cineconversaciones, una metodología desarrollada en el grupo de investigación, tratamos con artefactos y componentes curriculares, creando un camino de aproximación entre límites y fronteras a los que estamos sujetos todo el tiempo como migrantes o extranjeros en diferentes situaciones de la vida cotidiana.

Palabras clave: Migración - Redes educativas - Cotidianos - Cineconversaciones - Cine.

\section{Abstract}

The planet is today in the largest humanitarian crisis recorded by history and a large part of the worlds population is in displacement for extreme reasons, in search of survival.

Moreira alerts us to the fact that human mobility is a global phenomenon and of great dimensions. With Alves, we approach the topic in the context of the educational networks, because it is a way to know about the subject and to demystify prejudices. For that, Bobbio warns us that prejudice is an erroneous opinion. With Deleuze we think of cinema as a potente cultural artifact in conversations with students and in order to awareness them to a fact that is often part of the family history of each of us. And with Dubois, we bring the video as a device of questioning in the image-art tension provoking in the spectators the feeling of alterity.

Key words: Refugees - Educational Networks - The Daily Ones - Cineconversation - Movie.

\section{Caminhar... Conversar...}

O que é caminhar? Seria a mobilidade, a locomoção na qual nos pomos quando necessitamos nos deslocar de um ponto a outro? Um deslocamento que nos faz romper fronteiras, limites e medos? Caminhar pode ser, assim, um encorajamento. É nos colocar como andarilhos em busca de algo que, na condição de migrantes ou refugiados, nos permite entrar em 'espaçostempos 1 desconhecidos.

Esta expressão caminhar... foi extraída do filme Em busca do Ouro, de Chaplin (1925), 'vistoouvidosentidopensado' em uma sessão de Cineconversas. Na película, há um movimento migratório em busca de trabalho e ouro no Alasca, em que um dos personagens, falando dos conflitos nesses processos migratórios, diz que, as pessoas se põem a caminhar, caminhar, caminhar e a esperar, esperar, esperar, e que, na maioria das vezes, poucos conseguem desfrutar da ideia do ouro tão esperado.

O que é conversar? Onde reside a "potência do falso" (Deleuze, 2005)? Quem são os "personagens conceituais" ${ }^{2}$, (Deleuze; Guattari, 1992) que, como intercessores, no caminhar e conversar, fabricam diversas fabulações com 'discentesdocentes'? Como os 'usos' (Certeau, 2014) de filmes como artefatos curriculares, podem revelar as relações cotidianas tramadas nas múltiplas redes educativas que formamos e nas quais nos formam (Alves, 2015)?

Essas indagações atravessam nossa caminhada nesses 'fazeressaberes' no GRPesq "Currículos, redes educativas, imagens e sons", na linha de pesquisa "Cotidianos, Redes Educativas e

\footnotetext{
${ }^{1}$ Nas pesquisas com os cotidianos fomos percebendo que as dicotomias necessárias à criação das ciências na Modernidade, representavam limites ao que precisávamos criar. Com isto passamos a escrever assim os termos dessas dicotomias: com os termos juntos, em itálico, entre aspas simples, colocando no plural os termos e muitas vezes invertendo os termos tal como estamos habituados, a pronunciá-los, pelas marcas que os conhecimentos hegemônicos deixam em nós.

As palavras grafadas, juntas são para nós, do grupo de pesquisa nos/dos/com os cotidianos, um modo de perceber essas ideias que circundam os processos educativos nos cotidianos, como algo fluido, híbrido, não dicotomizada. Portanto, onde for encontrado palavras juntas e grifadas é porque estamos entendendo seus significados como uma relação de confluência. Este modo de escrever estes termos juntos e grafados - tais como os termos aprenderensinar, práticateoria, praticantespensantes, espaçostempos, conhecimentossignificações, docentesdiscentes, entre outros - é utilizado em pesquisas nos/dos/com os cotidianos e serve para nos indicar que, embora o modo dicotomizado de criar conhecimento na sociedade Moderna tem sua significação e importância, esse modo tem significado limites ao desenvolvimento de pesquisas nessa corrente de pensamento.

${ }^{2}$ Este conceito é utilizado por Alves, porém a autoria do mesmo é de Gilles Deleuze e Félix Guattari (1992), de quem a autora se apropria para entender que, para além de "fontes", as imagens, narrativas e sons permanecem muito tempo conosco para que se produzam ideias e conceitos. 
Processos Culturais", que pesquisa atualmente ${ }^{3}$ as relações entre processos curriculares e movimentos migratórios, no Programa de Pós-graduação em Educação (ProPEd), na Universidade do Estado do Rio de Janeiro - UERJ.

Quando nos colocamos em 'conversa' com Alves, Certeau, Deleuze, Guattari, Maturana e outros autores, trazemos para as pesquisas nos/dos/com os cotidianos, sentimentos, gestos, conflitos, sorrisos, palavras, indagações, imagens, sons, cheiros, toques, gostos, pensamentos, porque todos esses elementos são intrínsecos aos 'praticantespensantes' dos cotidianos (Oliveira, 2012).

Desenvolvemos em nosso grupo de pesquisa a ideia daquilo que chamamos de cineconversas ${ }^{4}$, ao assistirmos filmes que trazem a temática da migração, por exemplo, e conversarmos com as questões cotidianas que, inspiradas por esses filmes, são apresentadas pelo grupo estamos pondo em prática essa metodologia. As narrativas cinematográficas estimulam 'conversas' acerca dos processos que costuram os diferentes 'dentrofora' das escolas.

\section{Currículos e Movimentos Migratórios}

Dentre tantas questões sociais, estamos nos debruçando desde 2017 até o presente momento, aos movimentos migratórios, buscando entender como estes se transformam em questões curriculares nas escolas. Os movimentos migratórios são inspirações poéticas para sentir os currículos como movediços, e não algo estático e enrijecido. É pensar o currículo como um caminhar... esperar... caminhar..., e romper as fronteiras e limites do desconhecido. É 'sentirpensar' o currículo como uma pedagogia do encorajamento, numa ideia de pedagogia do atrevimento. Uma razão insolente para uma razão indolente, (Santos, 2002) e da ousadia e da crítica (Freire; Shor, 1987).

Temos o interesse de, a partir das distintas redes educativas, compreender os processos pelos quais situações sociais complexas - no caso a intensa migração de seres humanos, que por múltiplas razões, diferentes conflitos, pobreza e mudanças ambientais - se transformam em experiências curriculares. Este projeto de pesquisa se desenvolve em dois movimentos: primeiro, a realização de 'cineconversas', com filmes que mostram ondas migratórias no mundo, em escolas de alguns municípios do estado do Rio de Janeiro, dos quais participam docentes e discentes em formação. As 'conversas' presenciais e on line em torno de possibilidades e necessidades curriculares com o tema migração, se desenvolvem acerca de narrativas, imagens e sons usadas nos filmes, que nos servem como "personagens conceituais". As 'conversas' são o lócus principal da pesquisa, são um encontro de pensamentos, gestos e afetos. O segundo movimento, consiste na realização de oficinas de criação de vídeos acerca da questão mobilizadora - migração - com a participação de docentes em exercício e discentes em formação para a docência. Os dois movimentos acontecem como cursos de extensão.

Nesta pesquisa, somos fios na tessitura de uma rede plural e de múltiplas investigações envolvidas na compreensão de diferentes cotidianos e de tantas outras redes educativas. Por estar em conversas com essas diversidades, há uma profusão de noções, ideias e autores que, ao mesmo tempo, nos permitem a abordagem de questões que se articulam em ações e processos epistemológicosteóricos-metodológicos. Assim indicamos as seguintes ideias e processos: a multiplicidade dos cotidianos; a existência de diferentes redes de 'conhecimentossignificações'; a infinidade de criação de processos culturais nos tantos 'espaçostempos'; a ideia da existência de processos miúdos e sua visibilização, necessárias à vida humana; a compreensão de que os aprendizados não são processos estanques e que vão se modificando ao longo da vida, das políticas e memórias sobre 'práticasteorias' educativas; a existência de tantos 'dentrofora' das escolas; os inúmeros contextos de formação docente, em tantos outros 'espaçostempos', nas diversificadas 'práticasteorias' éticas, estéticas e políticas; os processos emancipatórios criados e vivenciados nos 'fazeressaberes' ordinários; a dimensão estética da existência na criação de si; as rupturas pós-estruturalistas e pós-colonialistas; o entendimento da presença de artefatos culturais em processos curriculares; os processos identitários dos 'praticantespensantes' dos

\footnotetext{
${ }^{3}$ Processos curriculares e movimentos migratórios: os modos como questões sociais se transformam em questões curriculares nas escolas', com apoio CNPq, Capes, Faperj, UERJ (entre 2017 e 2022) e coordenação de Nilda Alves.

${ }^{4}$ Lembramos que nosso projeto comum, no grupo de pesquisa - "Processos curriculares e movimentos migratórios: os modos como questões sociais se transformam em questões curriculares nas escolas" (2017-2022) - inclui um movimento a que chamamos, desde o projeto anterior, de 'cineclubes'. Recentemente, por proposta de uma das componentes do grupo - Rosa Helena Mendonça - passamos a chamar este movimento de 'cineconversas', pois de fato, sem seguir a tradição de cineclubes, o movimento que realizamos tem as 'conversas' em torno de temáticas introduzidas pelo processo de 'verouvirsentirpensar' os filmes como lócus central dessas pesquisas. Assim, não se trata de conhecer os filmes em si e discuti-los em sua historicidade, construção técnica, como obra artística de um criador etc - o que caracterizaria os processos realizados em um cineclube - mas de tê-los como iniciador de pensamentos que permitam as 'conversas'. Estas são conduzidas, tanto para a versão de realidades de migrações em ocasiões diferentes, em 'espaçostempos' diversos, por causas diferenciadas - que os filmes permitem, como, em especial, para como essas idéias permitem pensar processos de acolhimento de crianças e jovens - bem como seus pais - nas escolas brasileiras. Partimos das ideias que os 'praticantespensantes' das pesquisas como criações desses processos que conhecem ou que pensam ser possíveis de realizar.
} 
cotidianos; os valores como conhecimentos para a ação; o reconhecimento do Outro como um legítimo outro nas necessárias lutas de re-existência; narrativas docentes, singularidades e currículos criados nos cotidianos; crianças, jovens e adultos, de sua mais diferente origem, seja racial, étnica, territorial e religiosa, como sujeitos ativos criadores de si e do mundo; a valorização dos usos das imagens, sons e fabulações nos seus diversos planos, da mediação/criação das culturas educacionais como narrativas que atravessam todos as relações sociais contemporâneas.

Por isso, nossa pesquisa em educação, tratando das questões da migração, pretende entender a aproximação do tema mobilizador - migração - com os cotidianos nos 'fazeressaberes' escolares, no sentido de criar a partir da produção epistemológica-metodológica das 'Conversas', usando as cineconversas como dispositivo de sensibilização e reflexão acerca das questões sociais complexas, em que as narrativas por meio de imagens e sons (os filmes) nos colocam numa condição de críticos, de alteridade, acessando memórias e criando afetos.

As cineconversas, como dispositivo de sensibilização e reflexão, se dá pela afetação ao assistir a um filme e em seguida, conversar acerca das afetações provocadas por essa narrativa que envolvem os diferentes elementos da linguagem cinematográfica (imagem composta pela luz, enquadramentos, movimentos de câmera; relação espaçotempo como ritmo e ordenação na montagem; o som com sua ambiência sonora, trilhas e músicas; e por fim, a abordagem temática, com o argumento e roteiro) e ainda, a forma como essa narrativa é percebida por cada pessoa, de acordo com sua particular história de vida

Costumamos dizer que assistimos aos filmes para além do sentido da visão, por isso agrupamos as palavras ver, ouvir, sentir e pensar (filmes vistosouvidossentidospensados), com a ideia de não dicotomizar as sensações e compreendendo, ainda, que ao assistir a um filme, ele conecta todos os nossos sentidos e memórias, acessando assim as questões complexas abordadas nas narrativas.

A temática migração é uma dessas questões complexas que, como quaisquer outras, dentro de sua complexidade, na pesquisa com os cotidianos, não carece de um aprofundamento teórico nos seus aspectos antropológicos ou das ciências sociais, no sentido de investigar suas causas ou impactos, mas sim, buscar entender, no presente, nos acontecimentos cotidianos, como são criadas as relações entre os migrantes que chegam a uma escola e aqueles que os acolhem, neste ambiente educacional; e como estas relações se transformam em componentes (artefatos) curriculares.

\section{Migrantes ou Refugiados?}

É frequente, nos tantos cotidianos em que vivemos, tecermos 'conversas' em torno das diferenças entre refugiados e migrantes, tentando entender quais são as motivações ou particularidades que distinguem aqueles que decidiram/precisaram se mover na Terra. Nos mais variados 'espaçostempos' observamos conversas acerca de notícias de refugiados da Síria, da Venezuela e de tantos outros lugares, territórios... E o que sabemos sobre essas pessoas?

Os livros e as aulas de geografia nos/dos/com os cotidianos escolares estão repletos de ideias sobre os migrantes/refugiados. De modo muito geral, podemos dividir essas ideias em dois grandes blocos, sabendo que isto é uma grande simplificação de uma séria questão social. $O$ termo migrante se refere a toda pessoa que muda seu lugar de residência para outro por um tempo indeterminado. Essa busca geralmente é motivada por razões sociais, principalmente em busca de emprego. Ao refugiado é atribuído um conceito que está associado ao verbo refugiar (fugir, abrigar-se, escapar). O termo é usado com referência ao indivíduo que, devido a uma perseguição política, religiosa, ocasião de guerras, catástrofes ambientais ou ainda, uma situação outra na qual sua vida esteja em risco, ele se vê obrigado a solicitar refúgio em país estrangeiro.

Os seres humanos desde sempre migraram por vontade própria ou de forma obrigatória. Desde as transumâncias iniciais, grupos humanos se movimentavam por questões climáticas - temperaturas que variavam durante o ano, em regiões temperadas e frias; falta ou presença de água, nas regiões tropicais. Guerras locais também levaram a grandes movimentações. A busca econômica de mercadorias diversas aparece, com grande expressão, na Modernidade. Crises econômicas, como a falta de emprego que trazem grandes movimentações populacionais. No entanto, no presente, um número enorme de pessoas se move no planeta porque essas situações todas estão se somando ${ }^{5}$. É, por isto, que Moreira (2017) nos diz que:

A atual mobilidade humana no planeta atinge dimensões impressionantes e traz consequências absolutamente novas para os povos e ecossistemas do planeta. Ela está nada menos do que reconfigurando a humanidade. Basta mencionar os processos culturais de desenraizamento e

\footnotetext{
${ }^{5}$ Como vimos, pessoas migram por diversas razões e esse pode ser um movimento voluntário ou provocado. Quando elas partem de suas casas ou país de forma obrigada, esses são denominados migrantes forçados e podem solicitar a situação de refugiados no país para onde migram.
} 
deslocamento, de crises econômicas e identitárias; os conflitos étnicos, culturais e religiosos; as hibridizações, as fusões e os sincretismos; a exportação de gostos, costumes, valores e mercadorias; a profunda transformação na percepção de espaço e tempo; as mudanças na percepção de si, do outro e do mundo (Moreira, 2017, p. 8).

Entendemos assim que migração é o movimento dos seres humanos nos mais variados 'espaçostempos', pelos mais variados motivos e desde que o mundo é mundo. Foram criados alguns adjetivos para esse termo tão discutido no contemporâneo: pendular, sazonal, temporária, definitiva, espontânea e forçada. Compreendemos o processo migratório como um fluxo natural, muitas vezes de perspectiva individual, que passa pela realização de sonhos, aspirações de uma vida melhor, um novo emprego, aprender uma língua ou uma cultura diferente. E outras vezes são situações mais ásperas, criando fluxos ainda maiores: como o caso de secas, estagnação socioeconômica, falta de oportunidades de emprego e outros. Os motivos são múltiplos, o caso mais comum no Brasil foi o êxodo rural das décadas de 1950/1960 do nordeste para o eixo Rio-SP.

Virilio (2009) aponta informações que são relevantes para entendermos melhor esses processos migratórios atuais:

Últimas notícias. Em 2008, trinta e seis milhões de pessoas foram deslocados de seu lugar de origem, por razões climáticas, catástrofes naturais, conflitos. Um bilhão de pessoas estão previstas para os próximos cinquenta anos. Um bilhão de pessoas que vão se movimentar. Toda a situação do mundo vai ser perturbada. Perturbada pela crise de localização. As sociedades antigas estavam inscritas em um território, a terra natal. Hoje, elas estão à deriva por razão de deslocalização do emprego, por causa de conflitos que não acabam nunca. E, também, evidentemente, pela grande questão climática: o desaparecimento de arquipélagos, a submersão de litorais. É toda a história que se coloca a andar. É toda a história que se joga na estrada. Um bilhão de pessoas que se movem em meio século, nunca existiu antes (Virilio, 2009, p. 7 apud Alves, 2017, p. 3).

Observamos assim que a migração forçada é o conceito que mais se aproxima da ideia de refugiados. Para Milesi (2003) os refugiados são tão antigos quanto a humanidade, no entanto, foram muitas vezes 'esquecidos' nos relatos e nunca soubemos de fato quais foram as movimentações e os impactos em sua vida cotidiana, assim, em texto com Marinucci, afirmam que:

sabemos a existência de guerras, conflitos, imperialismo, colonialismo, perseguições políticas e religiosas, que perpassam a caminhada histórica de todo os povos. Infelizmente, as informações nem sempre se referiam as consequências que tais acontecimentos causaram a vida cotidiana das pessoas. Mesmo assim, sabemos que houve refugiados e deslocados em todas as épocas da história da humanidade. (Marinucci e Milese, 2003, p. 13).

$\mathrm{Na}$ contemporaneidade os refugiados se tornaram assuntos de relevância. Diferentes dos migrantes, a movimentação em situação de refúgio é, na maioria das vezes, uma decisão momentânea e não um projeto de vida. Existe uma latente necessidade de fugir, de sobreviver e nem que seja preciso passar por situações de perigo, como os refugiados do norte da África que atravessam o mar Mediterrâneo em botes, famílias inteiras que andam pelo Oriente Médio e pela Europa buscando uma nova oportunidade de viver.

O grande desafio da nossa sociedade é conseguir criar um modo mais igualitário. Para Milton Santos esse movimento é necessário porque "o acontecer próprio a um lugar não é indiferente ao acontecer próprio a um outro lugar, exatamente pelo fato de que qualquer que seja o acontecer é um produto do movimento da sociedade total". No entanto, as relações tão desiguais entre os países eclodem em consequências tão desumanas, destroem cidades inteiras, causam rupturas familiares e precisamos conversar acerca disso. É vital para a humanidade, para as relações sociais estabelecer conversas sobre nosso destino comum.

Acreditamos que precisamos de políticas que garantam para os migrantes, sejam refugiados ou não, sua cidadania em novos territórios. Propiciar à sociedade uma forma de reconhecer o Outro, como um legítimo outro nas suas diferenças, como afirma Maturana (2002), na criação de narrativas de enfrentamento aos preconceitos de xenofobia ${ }^{6}$. Para Bobbio (2002):

O preconceito é uma opinião errônea, no entanto, trata-se de um erro mais tenaz e perigoso do que qualquer outro, pois é um erro que corresponde a sentimentos e interesses de um grupo em

\footnotetext{
${ }^{6}$ Consiste na aversão a cultura estrangeira que pode causar perseguições, ataques ou até morte de imigrantes estrangeiros.
} 
relação a outro. Assim, o preconceito é uma predisposição em creditar como verdade algo que é um interesse ou um sentimento irrefletido. (Bobbio, 2002, p. 103 apud Andrade, 2006, p. 99).

Nós, da pesquisa com os cotidianos, não queremos reduzir ou simplificar a questão do refúgio, mas tentamos compreender que no ambiente educacional e nas inúmeras redes educativas, o que nos importa é nos aproximar das relações criadas entre aqueles que chegam e aqueles que acolhem, percebendo as situações de estrangeirismos de ambos os lados. Portanto, para nós dentro dos acontecimentos (Deleuze; Guattari, 2002) ${ }^{7}$ (Foucault, 2005) ${ }^{8}$, o que nos interessa é entender com quais astúcias, bricolagens, usos de diferentes artefatos como a linguagem, a cultura etc, criam 'conhecimentossignificações' e pautam outras agendas de conversas acerca da crescente necessidade de criação de políticas públicas que regulamentem, acolhem, criem currículos, para atender essas questões sociais complexas.

Compreender o processo de desterritorialização (Deleuze; Guattari, 1997), que submete as pessoas a deixarem seus territórios, pertences, culturas, 'conhecimentossignificações' que dominam, é tentar entender os tracejados das linhas de fuga que essas pessoas desenham, criando brechas, saídas, para um outro viver. Ao se desterritorializar pensando na perspectiva geográfica e afetiva, as pessoas saem de seus lares, seus campos de acomodação, para criar outros modos de sobrevivência, com adaptações culturais, sociais e psicológicas necessárias.

Para Deleuze e Guattari (1997), esse movimento de desterritorialização é a capacidade de criação de outra existência, no sentido de evidenciar as potências que se fragilizam ou estagnam pela territorialização, que mantém padrões ou condicionamentos. Nesse sentido, desterritorializar, transcende ao movimento de saída de um território para a ocupação de outros 'espaçostempos' na medida que o processo migratório é longo e repleto de caminhadas e esperas, de certezas e incertezas. Este será inventado com suas memórias, e mais que isso, com o despertar de outras capacidades e possibilidades de reexistência. Assim, os mares, oceanos, matas, não são limites ou obstáculos, eles fazem parte do território a ser deixado ou a ser conquistado, como plano de imanência, um plano de pensamento sobre seu modo de viver que será tecido numa rede de relações independentes, de diferentes grupos ou organizações, com uma liberdade e mobilidade, que muitas vezes o sistema político engessa, controla e dificulta as saídas. Assim Deleuze e Guattari (1997) nos ajudam a pensar esta questão, dizendo:

Vimos, todavia, que a terra não cessa de operar um movimento de desterritorialização in loco, pelo qual ultrapassa todo território: ela é desterritorializante e desterritorializada. Ela se confunde com o movimento daqueles que em massa deixam seu território. [...] Os movimentos de desterritorialização não são separáveis; os territórios que se abrem sobre um alhures e os processos de reterritorialização não são separados da terra que restitui territórios. (Deleuze; Guattari, p.113) [...] A desterritorialização de um tal plano não exclui uma reterritorialização, mas a afirma como a criação de uma nova terra está por vir. (Deleuze; Guattari, p.117).

Com a pesquisa nos/dos/com os cotidianos, nos interessa entender essa operação dos movimentos de desterritorialização como movimento político, crítico e de criação nas relações em coordenações consensuais de coordenações consensuais de ações (Maturana, 2002) num espaço singular e coletivo de linguajeio-narrativas-risos, olhares, escutas, cumplicidade, conflitos e afetos.

\section{Cineconversas: 0 cinema, narrativas, conversas e os processos da migração como artefatos curriculares}

Para Deleuze, cinema e realidade não são duas instâncias distintas. O cinema é descrito como "uma possibilidade, uma potência do real" (Guerón, 2011, p. 13), ou como "fabulações, uma potência do falso" (Gonçalves; Head, 2009). Gomes (2008) acredita que existe um pensamento positivista de que filmes são as janelas da realidade, sendo 'reprodutores da realidade'. No entanto, para Deleuze e o próprio Gomes isso seria impossível, já que o real é incriável, ele apenas existe. Assim, existe uma segunda perspectiva de Gomes (2008) de que a imagem no cinema não copia a realidade, o cinema cria realidades próprias, coerentes em sua estrutura narrativa, significando que filmes criam suas próprias

\footnotetext{
${ }^{7} \mathrm{O}$ acontecimento para Deleuze é um dos elementos dos princípios característicos da multiplicidade, que são hecceidades (quer dizer, individuações sem sujeito); é relação de movimento e de repouso entre moléculas e partículas, poder de afetar e de ser afetado (DELEUZE; GUATTARI, 2002).

8 "Acontecimento - é preciso entendê-lo não como uma decisão, um tratado, um reinado ou uma batalha, mas como uma relação de forças que se inverte, um poder confiscado, um vocabulário retomado e voltado contra seus usuários, uma dominação que se debilita, se distende, se envenena a si mesma, e outra que entra, mascarada. As forças em jogo na história não obedecem nem a um destino, nem a uma mecânica, mas efetivamente ao acaso da luta. Elas não se manifestam como as formas sucessivas de uma intenção primordial; tão pouco assumem o aspecto de um resultado. Aparecem sempre no aleatório singular do acontecimento."(Foucault, 2005).
} 
linguagens, sistemas e quadros próprios, nos quais são embutidos contextos específicos de 'espaçostempos' e grupos sociais.

$\mathrm{Na}$ perspectiva do pensamento em torno da Potência do Falso, ideia cara a Deleuze, as narrativas funcionam sempre como fabulações. Esses diversos autores entendem que as imagens criadas vão além da ideia de uma representação/apresentação, ampliando sua forma para imaginação. É por isto que Gonçalves e Head (2009, p. 17) afirmam: "em vez de criarem um possível realismo, abrem caminhos para fabulações, para a ficção como formas de aceder a um conhecimento." Ou seja, a capacidade imaginativa, coloca a nós, que produzimos imagens ou textos, a criar fabulações e narrativas acerca de qualquer situação. Somos, sempre, muito mais do que simples consumidores de imagens e textos, já que as usamos - no sentido que a esta palavra dá, Certeau (2014) - e com isto, movimentamos processos criativos de toda ordem, sobre nós mesmos e os outros, com que compartilhamos os 'espaçostempos' cotidianos.

Assim, temos trabalhado com a ideia de que o cinema é criador de um universo próprio acerca de uma circunstância e o meio em que se produziu. A partir dessa ideia, de que existem interferências na criação das obras fílmicas e da dificuldade de representação do real, conversamos em torno das obras cinematográficas entendendo que precisam ser considerados os 'espaçostempos' de sua criação.

$\mathrm{Na}$ pesquisa com a qual estamos envolvido ${ }^{9}$ à medida que 'vimosouvimossentimospensamos' um filme deixamos que ele nos interrogue - com suas imagens, sons, narrativas - e acerca delas conversamos entre nós e com os docentes e discentes que participam da pesquisa. Deste modo, entendemos que temos todos esses elementos do filme, já falado anteriormente como intercessores, "personagens conceituais", ideia apropriada na pesquisa, por nossa orientadora Nilda Alves (2012), a partir de uma ideia que encontramos em Deleuze e Guattari (1992), que nos explica:

os personagens conceituais são, assim, aquelas figuras, argumentos ou artefatos que entram como o outro - aquele com que se 'conversa' e que permanece presente muito tempo para que possamos acumular as ideias necessárias ao desenvolvimento de conhecimentos e a compreensão de significações nas pesquisas que desenvolvemos. Esses personagens conceituais aí têm que estar, para que o pensamento se desenvolva, para que novos conhecimentos apareçam, para que lógicas se estabeleçam. (Alves, 2012, pp. 12-13).

Entendemos que a tessitura das conversas provocadas pelas narrativas sustentadas por imagens e sons nos filmes, trazem possibilidades de criações múltiplas a partir das relações diversas entre o que foi 'sentidovistoouvidopensado' e as experiências individuais e coletivas dos que participam dos processos da pesquisa, na busca de um pensamento partilhado, fazendo surgir 'conhecimentossignificações' novos. Acreditamos que a partir desse artefato cultural e tecnológico seja possível 'sentirverouvirpensar' as tantas experiências vividas nos diversos cotidianos escolares e como neles se criam processos curriculares acerca da questão estudada.

$\mathrm{Na}$ pesquisa trabalhamos com a ideia de que nos cotidianos formamos inúmeras redes educativas e com elas nos formamos. Essas redes se relacionam entre si e permitem compreender melhor certas questões dos processos curriculares existentes. As redes educativas que entendemos serem de 'espaçostempos' de 'práticasteorias' são assim enunciadas: a da formação acadêmico-escolar; a das ações pedagógicas cotidianas; a das políticas de governo; a das ações coletivas dos movimentos sociais; a de criação e "uso" das artes; a das pesquisas em educação; a de produção e 'usos' de mídias; a das vivências nas cidades, no campo e à beira das estradas.

O projeto se desenvolve com a realização das cineconversas pelo grupo de pesquisa, junto a docentes em exercício e em formação ${ }^{10}$. Conversar com os filmes - com seus elementos componentes e acerca deles com os 'praticantespensantes' de cotidianos escolares assumindo-os como "personagens conceituais" é convocar narrativas nas quais diversos modos de 'sentirverouvir', 'praticarpensar' currículos, de sentir o mundo e os outros que nos fazem compreender modos re-existir nas condições de migrantes, que vez ou outra, também somos.

Nas cineconversas, assistimos vários filmes em torno do tema que pesquisamos, buscando melhor compreender como se inserem no 'fazerpensar' nas/das/com as escolas. Nessa perspectiva, trouxemos para esta 'conversa' acerca de currículo e migração, o filme brasileiro 'Cinemas, aspirinas e urubus', com direção de Marcelo Gomes, lançado em 2004, e que nos permite trabalhar com os movimentos migratórios.

\footnotetext{
${ }^{9} \mathrm{O}$ projeto tem por título "Processos curriculares e movimentos migratórios: os modos como questões sociais se transformam em questões curriculares nas escolas", com a coordenação de Nilda Alves e financiamento CNPq, CAPES, FAPERJ e UERJ (2017-2022).

${ }^{10}$ Os diversos membros do grupo de pesquisa, individualmente e coletivamente, desenvolvem inúmeras ações para 0 estudo da questão da migração e o modo com que se relaciona aos processos curriculares. Realizamos um vídeo sob o título "Os muitos mundos das migrações e os currículos escolares - iniciando o projeto" - acerca inúmeras dessas ações de preparação do grupo de pesquisa que pode ser visualizado em: https://vimeo.com/218818085
} 


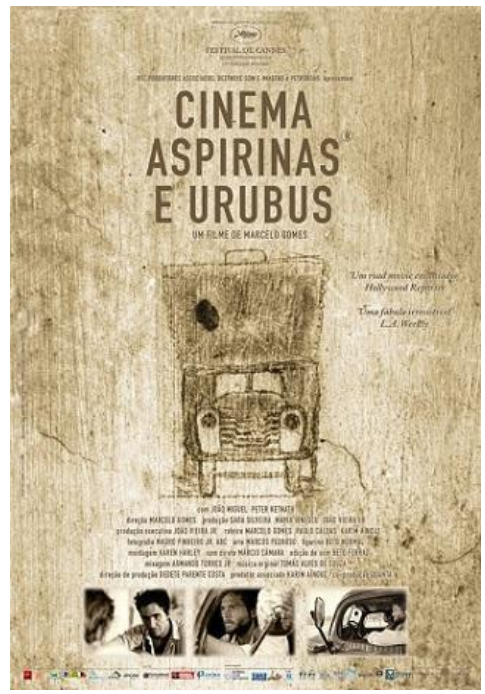

Imagem 1: Cartaz de divulgação ${ }^{11}$

A narrativa se passa no sertão nordestino em 1942. Traz a história de um alemão que vem para - Brasil, um migrante, fugindo da situação na qual a Alemanha se encontrava, de desemprego e iniciadora do que ficou conhecido como a Segunda Guerra Mundial. Trabalha como representante da Aspirina da Bayer no Brasil e monta uma estrutura ambulante, feita com um caminhão e artefatos que permitiam a projeção de pequenos filmes - documentários que mostravam a aspirina como excelente medicamento para uma série de doenças. Ele corta o sertão, visitando pequenas cidades do interior do Brasil, passando esses filmes à noite e vendendo seu produto.

O personagem alemão é apresentado como boa gente, que adora aquela condição de suposta liberdade, com todos os percalços de estar em terra estrangeira. Para suprir sua solidão, numa de suas andanças ele oferece carona para um sertanejo, que se torna um migrante, fugindo para São Paulo em busca de uma vida melhor, sem a miséria econômica e as condições ambientais da região. No transcorrer do filme e nos inúmeros acontecimentos cotidianos porque passam juntos - de necessidade de comida à picada de cobra - os dois tornam-se amigos, em situações que mostram suas diferenças, a partir de questionamentos de valores singulares de cada um.

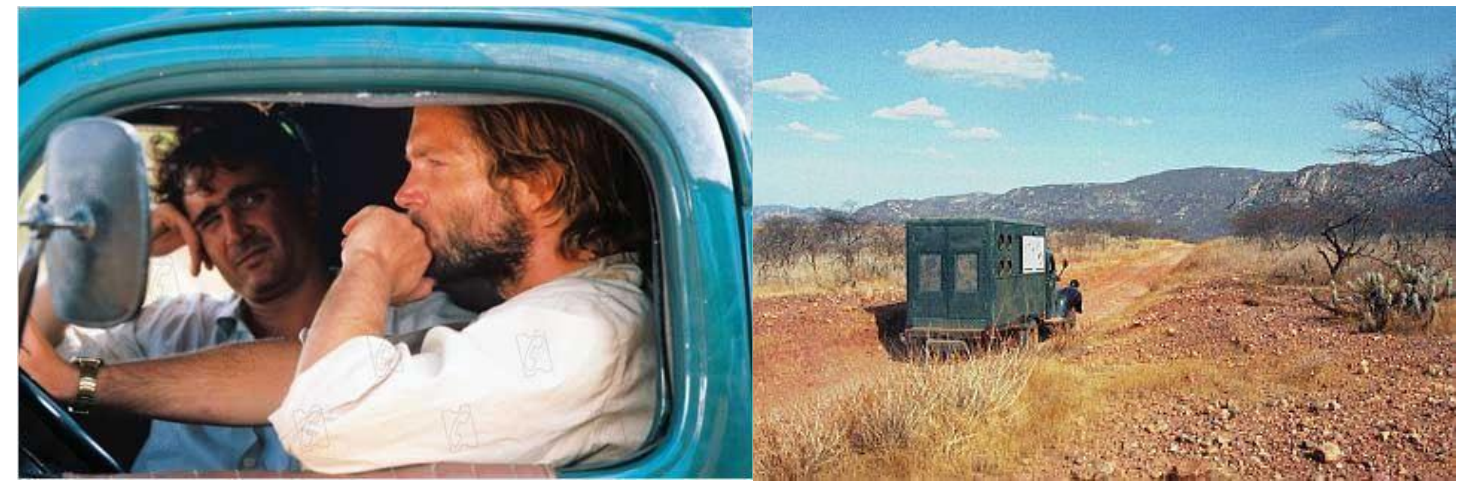

Imagem 2 e 3: Cenas do filme Cinema, aspirinas e urubus: os personagens principais e o caminhão.

Por ser tratar da história de migrantes, o filme revela os contrastes e astúcias que cada um dos personagens estabelece na convivência com os outros - pessoas e objetos - como artefatos e as bricolagens (Certeau, 2014) possíveis a partir das várias culturas que estão em convivência. Os contatos, no entanto, pela extrema pobreza - lembremo-nos: trata-se do sertão nordestino - estão sempre marcados pela necessidade de sobrevivência. Desse modo, o jovem nordestino, com seu linguajeio

11 Fonte: CINEMA, ASPIRINAS E URUBUS. Direção: Marcelo Gomes. Brasil. 2005, cor. Disponível em: $<$ https://www.google.com.br/search?q=filme+aspirina\&oq=filme++aspirina\&aqs=chrome..69i57j0l3.8065j0j4\&sourceid=c hrome\&ie=UTF-8>. Acesso em: 14 nov. 2017. 
próprio, na sua desterritorialização, busca saídas para a situação de opressão da seca, na sua longa viagem para São Paulo e, misturado ao linguajeio do jovem alemão, vendedor de aspirinas e fugindo da guerra, juntos, criam táticas (Certeau, 2014) que lhes permitem sobreviver juntos.

A montagem da tela - um lençol - em praças, transforma-se, sempre, em um acontecimento, de cidade em cidade, com a ajuda do breu das cidades do interior naquela época. Os pequenos filmes projetados mostram as 'maravilhas do Brasil', com foco na grande São Paulo (o que encanta o nordestino com este sonho). Mostra ainda, as mazelas cotidianas, exibindo pessoas que usam a pílula em busca do Fim para Todos os Males, slogan de vendas da aspirina. Ao término do curta-metragem, uma fila de pessoas é formada junto ao caminhão para comprar cartelas e mais cartelas desse medicamento.

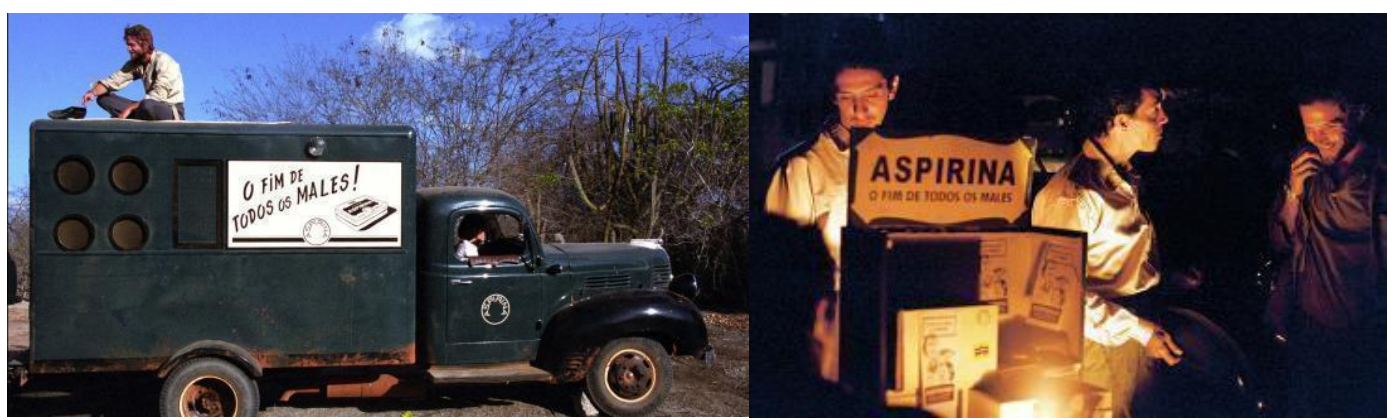

Imagem 4 e 5: Outra foto do caminhão que carregava e uma cena da sessão noturna sendo armada pela equipe técnica.

Cinema, aspirinas e urubus, permite transitarmos por 'espaçostempos' distintos, dilatados, imbricados, comprimidos (Deleuze, 2008), quando nos traz dois conflitos de distintas dimensões referentes à existência que levam os personagens à fuga de múltiplos 'espaçostempos' - da Alemanha ao sertão nordestino; deste a Amazônia, quando o Brasil entra em guerra com o Eixo (Alemanha; Itália; Japão); do jovem nordestino que sonha, sem saber como realizar, em ir para São Paulo para viver melhor. Mas o filme mostra muito mais: a possibilidade de encontro de dois jovens de diferentes culturas que vão se entendendo em suas tantas diferenças. E nesse encontro - bifurcado e de entroncamentos revela-se a arte (a possibilidade e a necessidade) de, nos 'fazeressaberes ' cotidianos - comer, conversar, caminhar pelas caatingas, ouvir as notícias da guerra no rádio, ouvir músicas, transar, rezar, seduzir a mulher, dirigir o caminhão, sentir a traição, transitar em um 'puteiro', fazer contas, curar picada de cobra, ver cinema, 'comprarvender' aspirinas (roubá-las também), - para, com táticas diversas, surgidas no instante (Certeau, 2014), ludibriar as forças das pequenas estruturas de poder para evitar deportação, migrar. Esses são movimentos e acontecimentos que se dão no inesperado e que potencializa os modos de existir.

\section{As conversas em torno do filme}

Após a exibição do filme, dando sequência à sessão de cineconversa, as conversas no grupo de pesquisa, com docentes e discentes, tratam das afetações provocadas pelo filme em nossas experiências e memórias despertadas pelas narrativas e poéticas das cenas e sequências que reúnem as questões que nos interessa tratar, como as astúcias, os encontros, as maneiras de criar com os cotidianos outros modos de viver, entendendo as coordenações consensuais das ações e o reconhecimento do Outro ou Outros como legítimos outros. Em se tratando de grupo de 'docentesdiscentes', nos faz 'sentirpensar' acerca de nossas 'praticasteorias' em sala de aula e nos diferentes 'dentrofora' das escolas e nas questões curriculares que emergem e devem ser provocadas na formação docente. Esta provocação por meio dos consumos e usos dos filmes como artefatos curriculares, sendo também artefatos de criação de narrativos por meio dos 'docentesdiscentes', tornando-os protagonistas de suas criações curriculares e de narrativas audiovisuais.

\section{Cenas do próximo capítulo}

A experiência do cineconversas nos apresenta o cinema no domínio de uma multilinguagem que se produz na base da 'imagemsommovimento', estando apto a "revelar ou a criar um máximo de 'imagemsonsmovimentos' diversos, e, sobretudo, a compô-las entre si através da montagem. Há imagens-percepção, imagens-ação, imagens-afecção, e muitas outras”, (Deleuze, 2008, p. 62). Estar coletivamente investigando as questões ordinárias tratadas no cinema é desvendar sensibilidades ocultas em imagenssonsmovimentos criados nesta arte que produz o mundo, permitindo a criação de 'espaçostempos' que nos levam ao exercício de alteridade.

As cineconversas podem ser tratadas como um dispositivo de sensibilização a partir da percepção do outro que supera a ideia reducionista do olhar para ampliar os sentidos que vão além do 
'verouvirsentir' para evocar memórias de pele, memórias olfativas, memórias de sabores, memórias de outros sons e outra imagens. Com isto, ao conversarmos com os docentesdiscentes que participam do projeto, abre-se a possibilidade de 'conhecersignificar' experiências já vividas e da possibilidade de outras experiências, ainda virtuais.

Observamos com a experiência desse filme, em especial, que aborda questões de estrangeirismo, astúcias e bricolagens nas relações entre os personagens e na criação de modos de existir com a "sessão do filme promocional da Aspirina" -, que nossa prática no grupo de pesquisa e nos nossos encontros nas escolas, de certo modo, se aproximam dos dois personagens do filme com que trabalhamos neste artigo: nas cineconversas o cinema toma outra proporção, já que os filmes são exibidos em 'espaçostempos' fora do cinema: na salas de aula, projetados a partir de outro suporte - o vídeo - e de artefatos mais 'domésticos' (o computador do grupo), sendo apresentados em outra superfície, no nosso caso, a parede da sala.

Nestas ações, as cineconversas desmistificam os usos de artefatos tecnológicos, sendo apropriados como artefatos curriculares que estão nos nossos cotidianos, e trazem as questões complexas dos cotidianos, como os processos migratórios, a partir das experiências de vida daqueles que circulam no ambiente escolar, como cada um de nós experimentamos isto no grupo de pesquisa.

Dessa forma, o que fazemos é buscar compreender como a questão migratória aparece nas escolas, em suas ações curriculares. Compreendemos que o migratório está em nós (somos todos migrantes ou temos sangue de migrantes - percebendo como isto se deu na história), que o cinema tem criado realidades migratórias em filmes há muito tempo, conversamos com docentes buscando saber acerca dos processos curriculares em que migrantes, migrações e suas causas complexas aparecem na escola.

As cineconversas, desmistificam a ideia, que temos que ser bom entendedor de cinema. $O$ que as ações com as cineconversas provocam é evidenciar nossas sensibilidades e atenção para sensações e sentimentos, as vezes adormecidos pelas tensões cotidianas e nos faz perceber essas tensões também como processo criativo, que é provocado pela metodologia da 'conversa', numa ideia de horizontalidade.

Nossa intenção não é concluir essa conversa, já que estamos em constante movimento, migrando entre territórios, 'espaçostempos', 'fazeressaberes', 'conhecimentossignificações 'e afetos.

O próximo capítulo trata-se dos acontecimentos cotidianos, o aqui e agora, o inesperado, improvisado, não controlado, como os próprios cotidianos e as pesquisas que neles que se criam e com eles se conversam.

Referências

Alves, N. (2002). Redes educativas, fluxos culturais e trabalho docente: o caso do cinema suas imagens e sons. Financiamentos CNPq, FAPERJ e UERJ, 2012-2017. (Projeto de Pesquisa). Tecer conhecimento em rede. Em: ALVES, Nilda. e GARCIA, Regina Leite. (orgs). O Sentido da Escola. Rio de Janeiro: DP\&A, pp.111 120.

Andrade, M. (2006). Por uma filosofia da educação a partir do conceito de tolerância. Rio de Janeiro: Pontifícia Universidade Católica do Rio de Janeiro, Doutorado em Ciências Humanas - Educação (Tese).

Bobbio, N. (2002). Elogio da serenidade e outros escritos morais. SãoPaulo: Unesp.

Certeau, M. (2014). A invenção do cotidiano - artes de fazer. Petrópolis: Vozes.

Cinema, aspirinas e urubus. Direção: Marcelo Gomes. Brasil. 2005, cor. Disponível em: https://www.google.com.br/search?q=filme+aspirina\&oq=filme++aspirina\&aqs=chrome..69i57j013.8065j0j4\&so urceid=chrome\&ie=UTF-8>. Acesso em: 14 nov. 2017.

Deleuze, G. (2008). Conversações. Rio de Janeiro: Ed. 34.

Deleuze, G.; Guattari, F. (2002). Os personagens conceituais. In: Deleuze, G.; Guattari, F. O (2002) que é filosofia? Tradução Bento Prado Jr. e Alberto Alonso Munoz. Rio de Janeiro: Editora 34, 1992: 81-109. Mil Platôs: Capitalismo e Esquizofrenia, Vol. 4. São Paulo: Editora 34.

Freire, P. y Shor, I. (1987). Medo e Ousadia Os cotidianos do professor. São Paulo: Ed. Paz e Terra, Disponível em: https://docs.google.com/document/d/0B_EJIHGqy14eaGZMY0ZZVDhQU09IQXkwRFIKaHB6UGpYaFZF/edit Acesso em: 07/02/2020.

Foucault, M. (2005). A ordem do discurso. São Paulo: Loyola.

Gomes, P. (2008). Cenários para a geografia: sobre a espacialidade das imagens e suas significações. In: Rosendahl, Z.; Corrêa; R. (Org). (2008). Espaço e Cultura: pluralidade temática. Rio de Janeiro: EdUERJ.

Gonçalves, M. (2009). HEAD, Scott. Confabulações da Alteridade: imagens dos outros (e) de si mesmos. In Devires Imagéticos, a etnografia, o outro e suas imagens. FAPERJ. Rio de Janeiro: Ed. 7 Letras.

Guerón, R. (2011) Da imagem ao clichê, do clichê a imagem: Deleuze, cinema e pensamentos Rio de Janeiro/RJ: NAU Editoria.

Maturana C. (2002). Emoções e Linguagem na educação e na política. Belo Horizonte: Ed UFMG.

Milesi, R. e Marinucci, R. (2003). Introdução. In: Refugiados: realidades e perspectivas. / organizado por Rosita Milesi. Brasilia: CSEM/IMDH, Edições Loyola.

Moreira, A. (Org). (2017). Religião, migração e mobilidade humana. Goiânia: PUC - Goiás.

Oliveira, I. (2012) Currículos e Pesquisas com os Cotidianos: o caráter emancipatório dos currículos 'pensadospraticados' pelos 'praticantespensantes' dos cotidianos das escolas. In: Ferraço, C. E. y Carvalho, J. M. (Org.). Currículos, Pesquisas, Conhecimentos e Produção de Subjetividades. Petrópolis: DP etAlli.

Ruge, L.; Forero, N. (2017). No final, tudo vai dar certo. In: A presença do migrante no Rio de Janeiro: O olhar do imigrante e do refugiado. Pastoral do Migrante e Coletiva Rede Migração Rio. pp. 20 - 23. 
REVISTA DE LA ESCUELA DE CIENICAS DE LA EDUCACIÓN., AÑO 16, NRO. 15, VOL 1, ENERO A JUNIO DE 2020. PÁGINAS 93 - 103. ISSN 2362-3349 (EN LÍNEA). CINECONVERSAS'- CRIANDO CURRÍCULOS COM FILMES DE MIGRAÇÃO. MARCELO FERREIRA MACHADO. MARÍA MORAIS. NOALE TOJA.

Santos, B. de S. (2012). Para uma sociologia das ausências e uma sociologia das emergências. Revista Crítica de Ciências Sociais. Número: 63, colocado online no dia 01 Out. 2012. Acesso em: 8 Abr. 2018. Disponível em: <http://journals.openedition.org/rccs/1285>; DOI : 10.4000/rccs.1285. 2012, p. 237-280

Virilo, P. (2009). Préface. In Virilio, P. Depardon, Raymond et alii. Terre natale - ailleurs commence ici. Actes Sud. Paris: Fondation Cartier pour l'art contemporain. 